\title{
Field testing of the QUB method for assessing the thermal performance of dwellings: in situ measurements of the heat transfer coefficient of a circa 1950s detached house in UK
}

\author{
Vasileios Sougkakis $^{1,2}$, Johann Meulemans ${ }^{* 3}$, Christopher Wood ${ }^{1}$, Mark Gillott ${ }^{1}$, and Tom \\ $\mathrm{Cox}^{2}$ \\ ${ }^{1}$ The University of Nottingham, University Park, Nottingham, NG7 2RD, UK \\ ${ }^{2}$ Saint-Gobain UK \& Ireland, East Leake, Leicestershire, LE12 6HX, UK \\ ${ }^{3}$ Saint-Gobain Research Paris, 39 quai Lucien Lefranc, F-93303 Aubervilliers, France
}

September 17, 2020

\begin{abstract}
In this paper the findings from a long-term field study of the thermal performance of a circa 1950s dwelling are presented and discussed. The study aimed at evaluating the robustness of the QUB method in the field under UK climatic conditions. A series of 147 QUB tests were performed during the whole heating period (September 2016 - March 2017) in a detached house located in the University Park campus, University of Nottingham considering two distinct conditions: as-built and with increased airtightness.

The QUB method was able to provide consistent and robust estimates of the Heat Transfer Coefficient (HTC) of the whole dwelling with approximately $80 \%$ of the results within $\pm 10 \%$ from the mean and more than $95 \%$ of the results within $\pm 15 \%$. The need to treat heat losses occurring through the ground when assessing the thermal performance of buildings through experimental diagnostics methods was highlighted, especially in uninsulated concrete slab floors. The method devised to isolate the ground floor heat losses from the whole building losses resulted in reduced dispersion of the adjusted Heat Transfer Coefficient with a coefficient of variation of $5 \%$ and $98 \%$ of results within $\pm 10 \%$ from the mean.
\end{abstract}

Keywords - QUB method; heat transfer coefficient; in situ measurements

\section{Introduction}

Under the Climate Change Act, the UK government set the legally binding target to reduce greenhouse gas emissions by $80 \%$ in 2050 compared to the 1990 emissions levels [1]. As the domestic sector is currently responsible for $27 \%$ of the country's final energy consumption [2] there has been significant effort in improving the thermal performance of new-built dwellings through tightening building regulations with regards to energy efficiency. However, it has been found that the design thermal performance is often inconsistent with the actual as-built thermal performance of a dwelling. This difference is commonly referred to as the 'performance gap' and is considered a significant risk that may compromise the efforts on meeting the carbon reduction targets and also affect the reputation and client satisfaction of the construction industry [3, 4]. In order to determine the magnitude of this gap which is related to the quality of the building fabric construction (i.e. excluding the effect of occupants and building use as well as the efficiency of building services) the Heat Transfer Coefficient (HTC) is used [5]. This is an indicator that accounts for both the transmission losses occurring through the building elements (including thermal bridges) and the infiltration losses of the building envelope. The HTC is a global parameter that represents the heat losses from the whole building per degree of temperature difference between the internal and external environment and is measured in $\mathrm{W} \mathrm{K}^{-1}$.

${ }^{*}$ corresponding author: johann.meulemans@saint-gobain.com 
Calculating the HTC of a dwelling is part of the regulatory process using the UK Government's Standard Assessment Procedure (SAP) and is based on information of the building geometry, location, surroundings and material properties [6]. The calculation is based on the energy balance of the dwelling and it takes into account factors such as U-values and respective areas of building elements, thermal bridges and the dwelling infiltration characteristics to determine the HTC of the building fabric.

In contrast, assessing the as-built performance is not as simple and straightforward. Several methods have been developed to determine the actual as-built thermal performance of the building fabric in situ. Perhaps the most widely used of these methods is the coheating test, a quasi-steady state method that determines the HTC of a building by maintaining a fixed internal elevated temperature using heaters and fans for a significant period of time (typically $2-4$ weeks) and monitoring the power required to do so as well as the external temperature and weather conditions. There is no standardised method for conducting the test, however the vast majority of coheating tests are now performed according to the protocol developed by Leeds Metropolitan University (now Leeds Beckett University) [7]. Furthermore, there is no standard method for analysing the results; several methods have been suggested for calculating the HTC and accounting for the solar gains that are the main source of uncertainty for the coheating tests. The main analysis techniques involve either performing multiple regression analysis where the power input is the dependent variable and the solar irradiance and the temperature difference are the independent variables, or performing the so-called 'Siviour method' where a collective term representing the power input minus the solar gains is the dependent variable and the temperature difference is the independent variable. A review of the analysis methodologies can be found in literature [8-11]. Despite the wide acceptance of the method by industry and research institutions, it is not considered practical as it involves long testing periods when the occupants are required to leave their property and it is restricted during the heating season when the external temperature and the levels of solar radiation are typically low. The scope for a more practical, less time and resources consuming alternative of the coheating test that could be applied for quality assurance purposes has been highlighted as early as 2011 when it was included in the recommendations of the Good Homes Alliance Monitoring Programme report [12]. This was one of the first wide scale research programs investigating the post construction performance of dwellings that involved partners from industry, academia and UK government. One of the house builders involved in the programme suggested that "there would be benefit in exploring development for a simplified method that had the target to provide $80 \%$ of the accuracy/results with only $20 \%$ of the commitment and complexity in terms of time, resources and cost" ( [12], p. 24).

Several in situ measurement methods have been recently developed and/or improved to assess the thermal performance of buildings (e.g., see work carried out within IEA EBC Annex 58 on dynamic methods [13] and then further developed within IEA EBC Annex 71 (e.g., see [14,15])). The applicability and suitability of one such method, the QUB method, to measure the actual whole building thermal performance under the UK climate conditions is discussed in this paper. QUB is an in situ disruptive dynamic measurement method developed to determine the HTC of a building within a much shorter period, usually within one night. Since it was first developed, the method has been tested under different conditions and settings, validated against numerical models as well as other experimental methods and was further refined. The ability of the QUB method to provide reliable results, has been demonstrated numerically [16-18] and experimentally in a climate chamber under steady conditions where its performance was compared against results obtained with coheating tests $[19,20]$. A good agreement was observed between the two methods and the QUB method was considered suitable to assess the actual thermal performance of buildings with reasonable accuracy. Ghiaus and Alzetto [17] further investigated the uncertainty related to the QUB measurements. They devised a method to minimise the expected (a priori) uncertainty by accounting for the test duration and the power input w.r.t. the building tested and the weather conditions. Several studies have been previously reported on the performance of the method under actual climatic conditions in different regions of Europe [16,21-23]. A concise description of the different tests and validation experiments is provided by Alzetto et al. [24]. These studies demonstrated the applicability of the QUB method to measure the building thermal performance and its suitability to be used as a research tool. It was highlighted however that there was further need to investigate the performance of the method over a long-term period in order to evaluate its effectiveness in practice [20]. If the method was found to be reliable and robust enough in the field, it could then easily be used on a wider scale as part of a quality assurance process set by the housebuilding industry to provide evidence of the building envelope construction quality. The QUB method lends itself for such use due to its short duration and efficient post-processing analysis.

The aim of the work presented in this paper is to evaluate the robustness of the QUB method in the field under UK climatic conditions. It is part of a two-year campaign where the applicability of the QUB method was investigated in two detached single family dwellings: first in an uninsulated dwelling and then in a well-insulated property. The findings from the first part of the campaign are discussed here where QUB tests were conducted in an uninsulated property between September 2016 and March 2017. The main objectives were two-fold: $(i)$ to assess the repeatability of the results, i.e. the ability of the method to provide consistent results on a day to day basis; (ii) to evaluate the robustness of the method and to identify potential effect of weather parameters 
on the resulting HTC.

The testing was conducted under two distinctive levels of airtightness, baseline and increased airtightness configuration, in order to evaluate the contribution of the infiltration losses and investigate the effect of the wind conditions on the HTC of the dwelling under different infiltration characteristics.

\section{The QUB method}

The QUB method was developed to determine the as-built HTC of dwellings within one night without occupancy. The test commences after sunset and finishes before sunrise of the following day (Figure 1b). The principle of the QUB method is based on a single resistance and capacitance model [24] where the building is represented by a global thermal resistance R (the reciprocal of the HTC of the building) and a global capacitance, $\mathrm{C}$ (the internal heat capacity) (Figure 1a). Internal and external temperature nodes ( $\mathrm{T}_{\text {int }}$ and $\mathrm{T}_{\text {ext }}$ respectively) are considered homogeneous and heat exchange between the two nodes occurs through the thermal resistance, $\mathrm{R}$. Temperature evolution is described as a single decaying exponential.

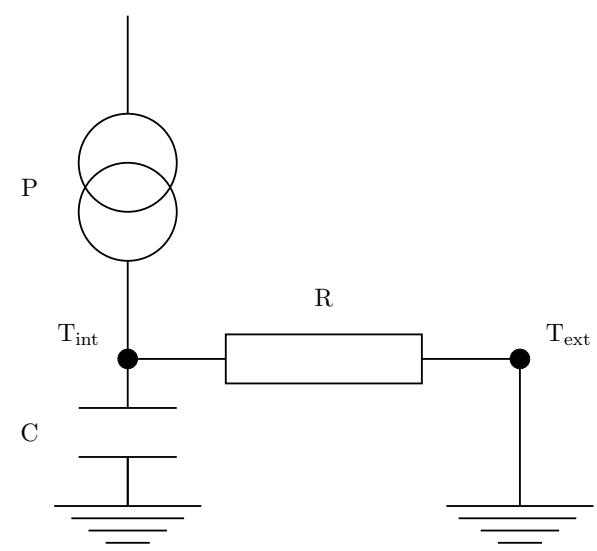

(a) RC model

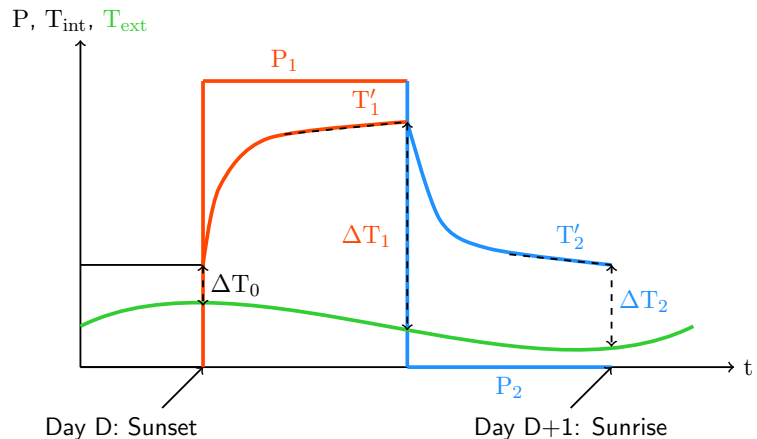

(b) Evolution of power and temperatures

Figure 1: Schematic view of the QUB method

It is acknowledged that this model is crude and in reality the thermal behaviour of the envelope is much more complex. A more detailed representation would involve a larger RC network with more nodes and, hence, more time constants. The thermal response of the building in that case would be the superposition of a number of decaying exponentials. However, it has been shown that after a sufficient amount of time the single RC model provides a good approximation of the building conditions and the model becomes valid [16,17,24]. Based on the single RC model, the energy input, $\mathrm{P}$, is heat lost through the envelope and stored/released by the thermal mass of the fabric (Equation 1):

$$
P=\frac{T_{i n t}-T_{e x t}}{R}+C \frac{d T_{i n t}}{d t}
$$

Where, $\mathrm{P}$ is the power input (in $\mathrm{W}$ ) in the building, $\mathrm{T}_{\mathrm{int}}$ and $\mathrm{T}_{\text {ext }}$ are the internal and outside temperature (in $\mathrm{K}$ ) respectively, $\mathrm{R}$ is the global resistance $\left(\right.$ in $\mathrm{K} \mathrm{W}^{-1}$ ) of the building (the reciprocal of the $\mathrm{HTC}$ that accounts for the transmission and infiltration losses) and $\mathrm{C}$ is the apparent heat capacitance (in $\mathrm{J} \mathrm{K}^{-1}$ ) of the envelope.

Equation 1 involves two unknowns, $\mathrm{R}$ and $\mathrm{C}$. These can then be determined by using two different constant powers in two different phases of equal duration (respectively noted 1 and 2 in Figure $1 \mathrm{~b}$ ) and solving a system of two equations. The HTC, noted H, can then be derived by the following formula (Equation 2):

$$
H=\frac{T_{2}^{\prime} P_{1}-T_{1}^{\prime} P_{2}}{T_{2}^{\prime} \Delta T_{1}-T_{1}^{\prime} \Delta T_{2}}
$$

Where $P_{i}$ is the power input during phase $i, T_{i}^{\prime}$ is the slope of the temperature profile at the end of phase i (i.e., for $t \in\left[t_{i_{0}}+d_{i}-\min \left(d_{i} / 2, \tau\right), t_{i_{0}}+d_{i}\right]$ where $t_{i_{0}}$ is the beginning of phase $i, d_{i}$ the duration of phase $i$ and $\tau=2 \mathrm{~h}$ ) and $\Delta \mathrm{T}_{\mathrm{i}}$ is the internal to external temperature difference at the end of phase $\mathrm{i}$ [19].

The Taylor series method for uncertainty propagation is used to compute the relative uncertainty associated to the HTC [25]. It is apparent that for an accurate measurement of the HTC, there needs to be an accurate 
measurement of the power input, P. To do this and avoid unwanted heat gains that are difficult to quantify (such as solar gains, metabolic heat gains from occupants etc.) the test is carried at night in an empty unoccupied dwelling without additional heat sources. To simplify matters there is no power input in phase $2\left(\mathrm{P}_{2}=0 \mathrm{~W}\right)$, i.e. this is the free cooling phase.

Further development of the method involved the use of a quadrupole model based on the same assumptions to investigate the thermal response of the building in short duration. A detailed description of the model is given by Alzetto et al. [16]. This approach led to establishing specific criteria considering the testing conditions with regards to the power input and the internal and external temperature that, when met, allow for a reliable measurement to take place. These criteria have been summed to a dimensionless parameter inherent to the QUB method, the $\alpha$-parameter, $\alpha$ (e.g., see [16,24] and references therein) (Equation 3).

$$
\alpha=1-\frac{H_{\mathrm{ref}} \Delta T_{0}}{P_{1}}
$$

Where $\mathrm{H}_{\text {ref }}$ is the reference HTC (theoretical or determined experimentally) (in $\mathrm{W} \mathrm{K}^{-1}$ ), $\Delta \mathrm{T}_{0}$ is the initial temperature difference between the interior and the external environment (in $\mathrm{K}$ ) and $\mathrm{P}_{1}$ is the power input during the heating phase (in W).

It has been demonstrated that the $\alpha$-parameter has minimum effect on the resulting HTC for values 0.4 $\leq \alpha \leq 0.7$, while for $\alpha \geq 0.7$ there is usually an overestimation of the HTC mostly at very short tests [19,21,24]. Hence, meeting this criterion is considered a measure of confidence level for test accuracy.

\section{Methodology}

\subsection{Description of the house}

The tests were carried in a circa 1950s detached house located at 5, Wortley Close at the University Park Campus, University of Nottingham. The property is a two storey L-shaped detached house. The wall construction is of twin layer brick construction with a $50 \mathrm{~mm}$ unfilled masonry cavity and the floor is solid uninsulated concrete slab. It has a cold pitched roof with insulation at ceiling level and the windows are single glazed. The house has North-East orientation and ground floor area of approximately $93 \mathrm{~m}^{2}$. The internal volume of the house is $447 \mathrm{~m}^{3}$ and the internal envelope area, i.e. the area of walls, floor and ceiling enclosing the heated space and separating it from the external environment is about $416 \mathrm{~m}^{2}$. The building's total heated floor area is approximately $170 \mathrm{~m}^{2}$ and the window to wall ratio is about $18 \%$. All measurements refer to the internal side of the building envelope disregarding any internal partition walls and floors as suggested by the Standard Assessment Procedure (SAP) [6]. The plans and external views of the house are shown in Figure 2 and Figure 3 respectively.

The house has a mostly open exposure to the sky without any obstacles blocking any part of the sky-view. It should be noted that the North-East façade of the building is sheltered from tall trees that could partially obstruct the sky-view of the roof. However, this is not considered significant as the trees were leafless for most of the testing period.

The HTC of the house was determined under two different airtightness configurations: a) baseline (as-built including minor interventions, i.e. repairing of broken window glass by applying boarding) and b) with increased airtightness by applying polyethylene films across the entire window reveals, in order to prevent air leakage through the old window frames (Figure 4). The air permeability at $50 \mathrm{~Pa}, \mathrm{q}_{50}$, was measured by performing a fan pressurisation test (commonly known as 'blower door' test) according to the procedure set by the Technical Standard L1 by the Air Tightness Testing \& Measurement Association [26] based on the BS EN ISO $9972: 2015$ Standard [27]. The test involves applying a $50 \mathrm{~Pa}$ pressure differential by means of a fan and measuring the air flow rate required to do so. The building envelope may either pressurised or depressurised or both to obtain the air permeability. The air permeability of the test house was measured at $9.3 \mathrm{~m}^{3} \mathrm{~m}^{-2} \mathrm{~h}^{-1}$ for the baseline configuration (corresponding airtightness at $50 \mathrm{~Pa} \mathrm{n}_{50}=8.65 \mathrm{ach}$ ) and approximately $6.5 \mathrm{~m}^{3} \mathrm{~m}^{-2} \mathrm{~h}^{-1}\left(\mathrm{n}_{50}=\right.$ $6.05 \mathrm{ach}$ ) for the increased airtightness configuration.

\subsection{Monitoring equipment and testing protocol}

In order to perform a QUB test the following parameters need to be monitored: zone air temperatures, external air temperature and the power input. Air temperatures were monitored with PT100 platinum RTD sensors and the energy consumed by the heaters was monitored with the use of Wh energy meters. HFP01 heat flux plates from Huksefklux were installed on the surface of building elements to measure the heat flows during the test. Data were stored in two Datataker DT85 loggers and a DT80 logger at 1 minute intervals. Weather conditions were recorded with the use of a weather station installed on the roof of a neighbouring house approximately 30 meters away from the test house. The weather station comprised a WSD1 sensor by EML and a Skye rht+ 


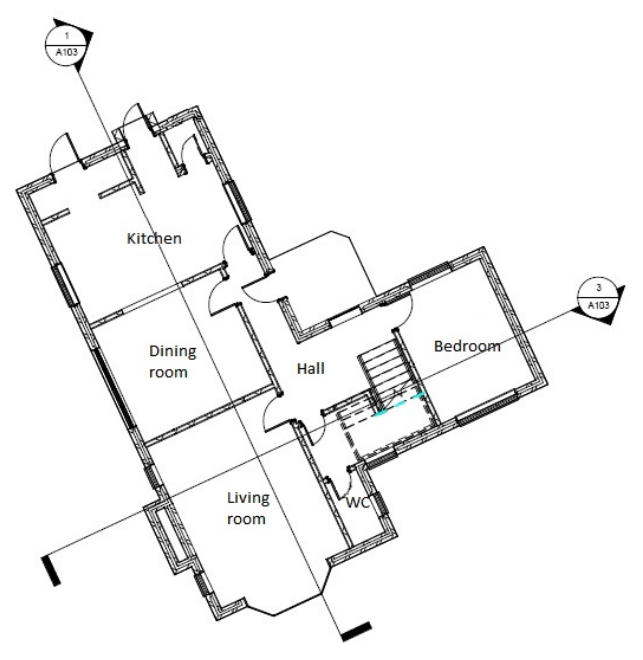

(1) $\frac{00-\text { Ground Floor }}{1: 100}$

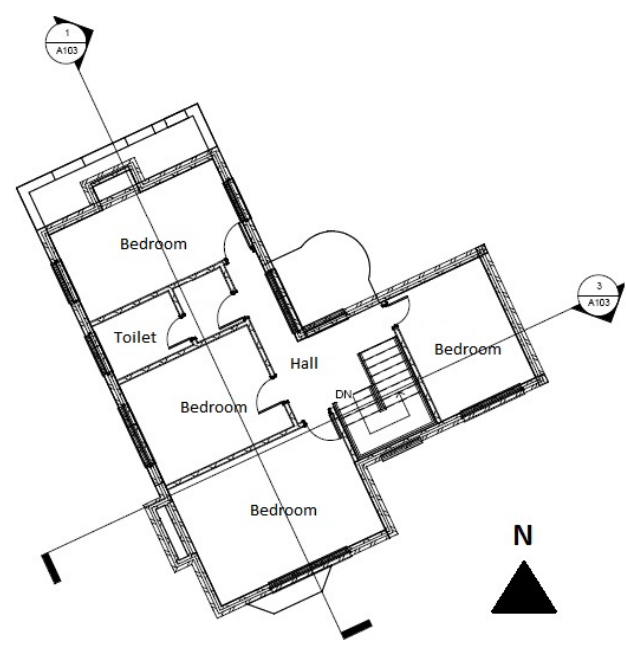

(2) 01_First Floor

Figure 2: Ground Floor (left) and First Floor (right) plans
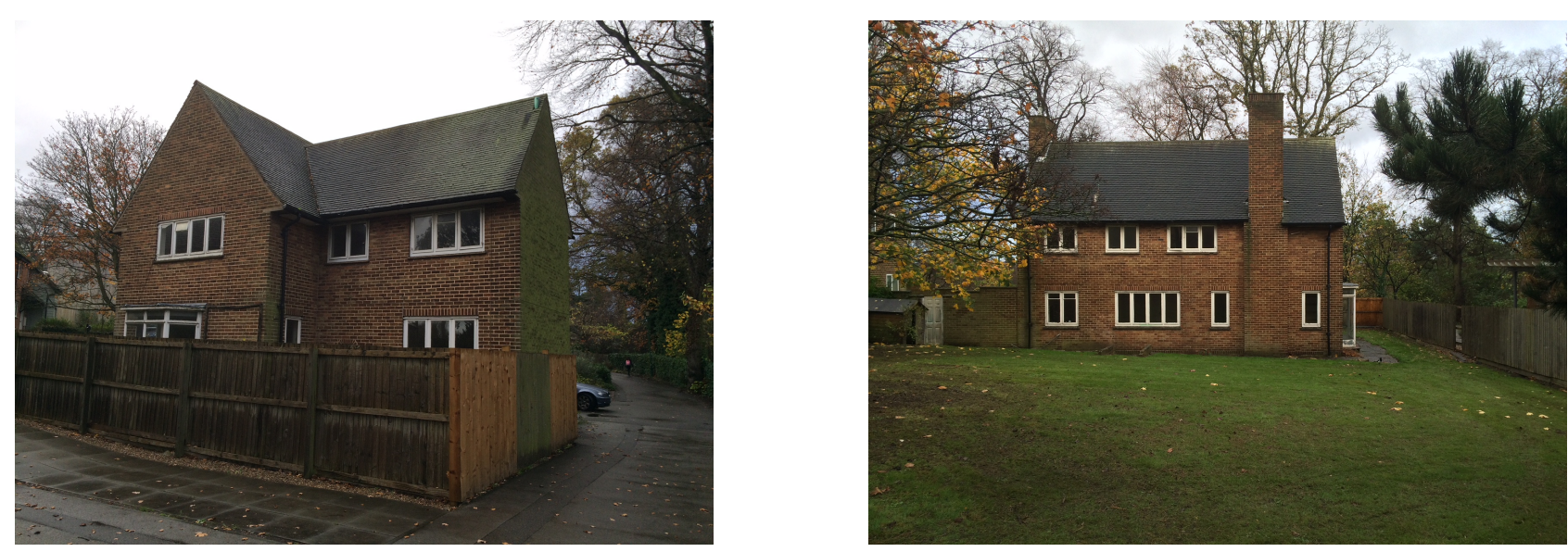

Figure 3: External view of the house from the South-East (left) and West (right)
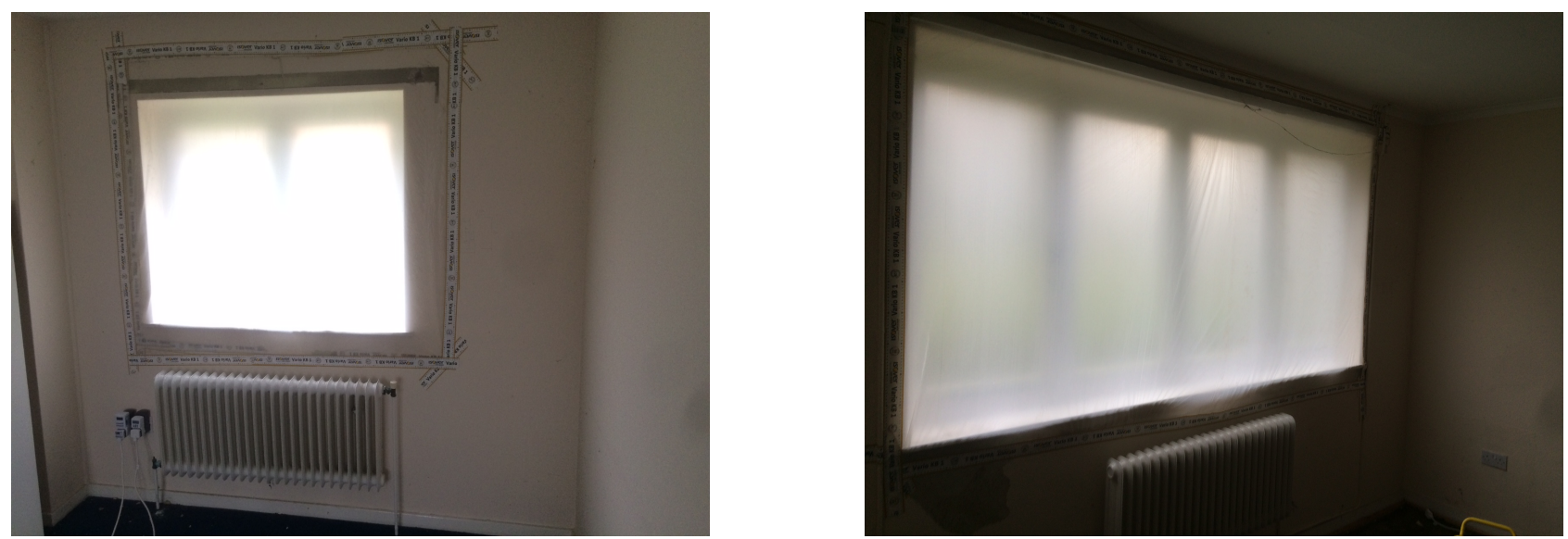

Figure 4: Polyethylene film applied on windows to increase the airtightness of the fabric

sensor for measuring temperature, relative humidity, wind speed and direction. Levels of horizontal and vertical south solar irradiance were monitored with the use of CMP3 Kipp \& Zonen pyranometers and precipitation 
levels with the use of an ARG100 rain gauge.

The tests were conducted with the use of electric resistance fan heaters with three power settings $(650,1300$ and $2000 \mathrm{~W}$ ). The heaters were distributed in the house accordingly and different power settings were used based on room volumes in order to achieve homogeneous temperatures throughout the building. In addition, more power was required to be installed at the ground floor due to the warm air rising and transferring heat to the first floor. It is acknowledged that it is not possible to achieve absolutely homogeneous temperatures; these measures resulted in internal room temperatures that were reasonably close (within $\pm 1 \mathrm{~K}$ throughout the building in most cases). The heaters were connected to timers that were programmed accordingly to initiate the heating phase (timers switching the heaters on) and the cooling phase (timers switching off the heaters). A constant power input, $\mathrm{P}_{1}$, of approximately $11 \mathrm{~kW}$ was used throughout the whole testing period. This was the maximum allowable power input imposed by the electrical installation of the house. An example of the temperature and the power evolution during a typical QUB test is shown in Figure 5.

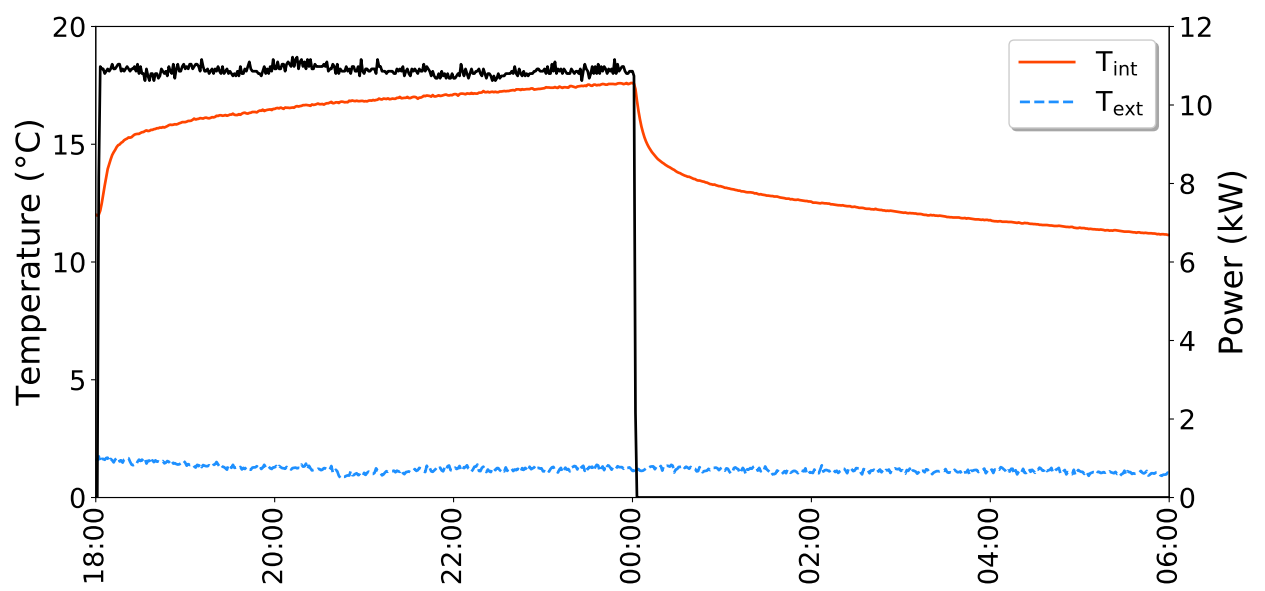

Figure 5: Evolution of power and temperatures during a typical QUB test

To ensure identical conditions for all tests and to avoid the need for operatives to enter the building a second set of electrical resistance fan heaters were used for background pre-heating. This second set of heaters were controlled by thermostatic PID controllers and timers, programmed to ensure the building maintained a constant temperature prior to the start of a test and they were switched off for the duration of the test. The two sets of heaters installed in a room can be seen in Figure 6.

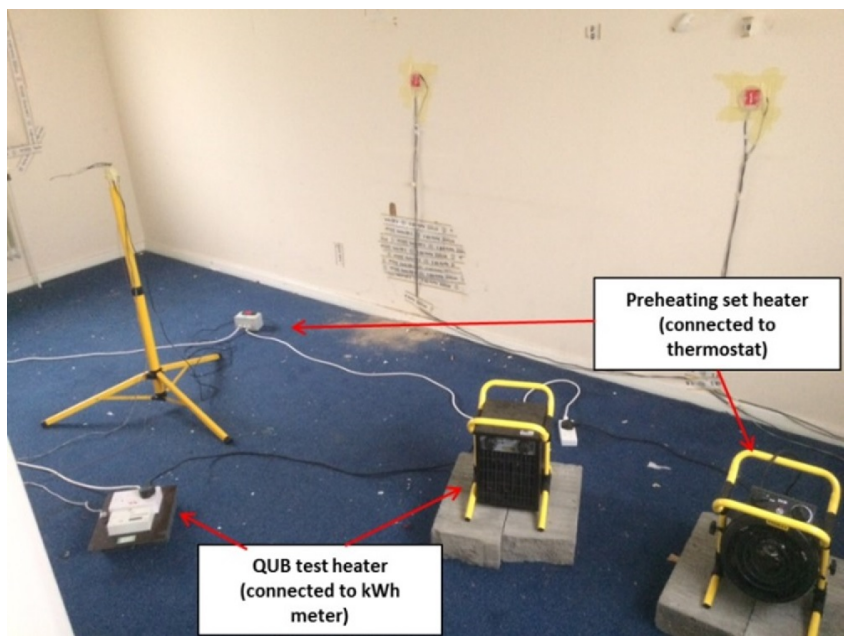

Figure 6: Installation of the preheating set and the QUB test set of electric fan heaters

The house was tested on a daily basis from the end of September 2016 until the end of March 2017 with minor interruptions during this period. Due to the fact that the duration of the night changed over the different months, the duration of the QUB test was also amended. However, the minimum duration of the heating phase at any test was five hours (i.e. the minimum test duration was ten hours as the test consists of two phases of equal duration); it has been demonstrated that for heating duration higher than 4 hours the results were not affected by values of the $\alpha$-parameter between 0.4 and $0.7[17,19]$. The different configurations as well as the 
different test durations are shown in Table 1.

\begin{tabular}{|c|c|c|c|c|}
\hline Configuration & $\begin{array}{c}\text { Air permeability } \\
q_{50}\left(\mathrm{~m}^{3} \mathrm{~m}^{-2} \mathrm{~h}^{-1}\right)\end{array}$ & $\begin{array}{l}\text { Number } \\
\text { of tests }\end{array}$ & Period & $\begin{array}{c}\text { Heating duration } \\
(\mathrm{h})\end{array}$ \\
\hline \multirow[t]{2}{*}{ Baseline } & \multirow[t]{2}{*}{9.3} & \multirow[t]{2}{*}{58} & $22 / 09 / 2016-10 / 11 / 2016$ & 5 \\
\hline & & & $11 / 11 / 2016-05 / 12 / 2016$ & 7 \\
\hline \multirow{2}{*}{$\begin{array}{l}\text { Increased } \\
\text { airtightness }\end{array}$} & \multirow[t]{2}{*}{6.5} & \multirow[t]{2}{*}{89} & $07 / 12 / 2016-30 / 01 / 2017$ & 7 \\
\hline & & & $31 / 01 / 2017-21 / 03 / 2017$ & 6 \\
\hline
\end{tabular}

Table 1: Test configuration and heating duration

It was attempted that each test would be conducted with a value of the $\alpha$-parameter within the recommended range $(0.4 \leq \alpha \leq 0.7)$ in order to ensure measurement accuracy and avoid systematic overestimation of the HTC. When conducting the tests, conditions for each test were designed for a value of 0.5 for the $\alpha$-parameter. Considering the limitation in the available power in the house and an initial estimation of the reference HTC (i.e., $\mathrm{H}_{\text {ref }} \approx 550 \mathrm{~W} \mathrm{~K}^{-1}$ ), a value of 0.5 for the $\alpha$-parameter can be obtained for a temperature difference of approximately $10 \mathrm{~K}$ since $\Delta \mathrm{T}_{0}=(1-\alpha) \mathrm{P}_{1} / \mathrm{H}_{\text {ref }}$.

As the power input was kept constant due to the aforementioned restrictions of the electrical installation, this effectively meant that the starting internal temperature was adjusted with respect to the forecasted external temperature in order to achieve an initial temperature difference of approximately $10 \mathrm{~K}$. Despite the fact that an automated process was established for the testing procedure, there was still the need for an operative to manually adjust the thermostats regulating the preheating temperature prior to each test based on the expected conditions.

Preheating temperatures ranged from $12.2^{\circ} \mathrm{C}$ to $23.8^{\circ} \mathrm{C}$ with an average value of $18.4^{\circ} \mathrm{C}$. However, adjusting the thermostats on a daily basis was not always feasible, mainly on weekends, resulting in several tests failing to meet the requirement on the alpha parameter.

Furthermore, the required temperature for each test was determined through an estimation of the expected value of the $\alpha$-parameter using an estimate of the reference HTC (prior to any testing). The values of the $\alpha$-parameter for the tests reported here were again calculated using the mean HTC of all tests for each configuration. The discrepancy between the estimated HTC used prior and the average HTC used after the testing contributed in some of the tests falling outside the recommended limits of the $\alpha$-parameter.

In total 147 tests were conducted, out of which 133 were within the recommended values for the $\alpha$-parameter; this corresponds to $90 \%$ of all tests.

\subsection{Ground losses}

The internal starting temperature was changed according to the external temperature on any given test day such that the alpha parameter lay within the recommended range. Effectively, this meant reducing the internal temperature on colder nights and increasing it on warmer nights by adjusting the thermostats on the second set of heaters. Since the ground temperature did not follow the external temperature variation, it was assumed that the floor heat loss, and the subsequent HTC, was higher on warmer nights as a result of the higher internal temperatures, increasing potentially the variation on the resulting HTC. For this reason, a method was devised to isolate heat loss from the ground from the total building heat losses and evaluate the resulting adjusted HTC.

To do this, the average heat flux from the whole floor was determined by installing ten heat flux plates in different locations of the floor (see Figure 7). Trethowen and Delsante [31] showed that the majority of heat losses from an uninsulated concrete slab-on-ground floor in wet soil occurs within a perimeter zone of $50 \mathrm{~cm}$ width, while losses occurring from the remaining zone up to $1 \mathrm{~m}$ width were significantly reduced and the losses from the remaining core area were even less. For this reason, a perimeter zone of $0.5 \mathrm{~m}$ (marked with the blue line) corresponding to approximately $25 \%$ of the total floor area, and a core area representing $75 \%$ of the total floor area $\left(70 \mathrm{~m}^{2}\right)$ were defined as shown in Figure 7 . Two sensors were located within the perimeter zone at a distance of $10 \mathrm{~cm}$ from the outer walls while the remaining eight sensors were located in the core area at various distances from the external walls. The average heat flux from the whole floor was determined considering the area-weighted average of the eight core sensors representing $75 \%$ of the floor area and the two perimeter sensors representing $25 \%$ of the floor area.

The obtained values of average heat loss from each sensor for a typical week of testing is shown in Figure 8. It can be seen that despite some variation in the heat loss from the core area sensors, losses from the perimeter zone were markedly higher consistently. Furthermore, there seems to be no significant relationship between the distance of the core sensors from the outer walls and the amount of heat losses. This suggests that the 


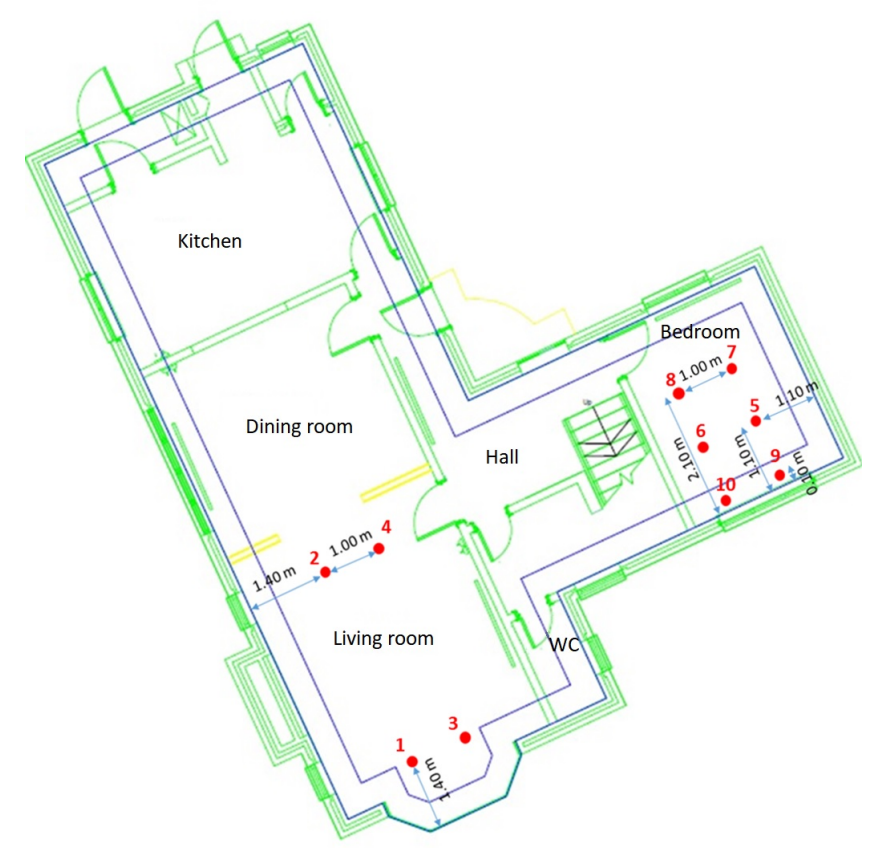

Figure 7: Location of heat flux sensors installed on the floor perimeter and core area

choice of the $50 \mathrm{~cm}$ boundary for defining the perimeter zone as recommended by Trethowen and Delsante [31] is considered suitable for the purpose of this analysis.

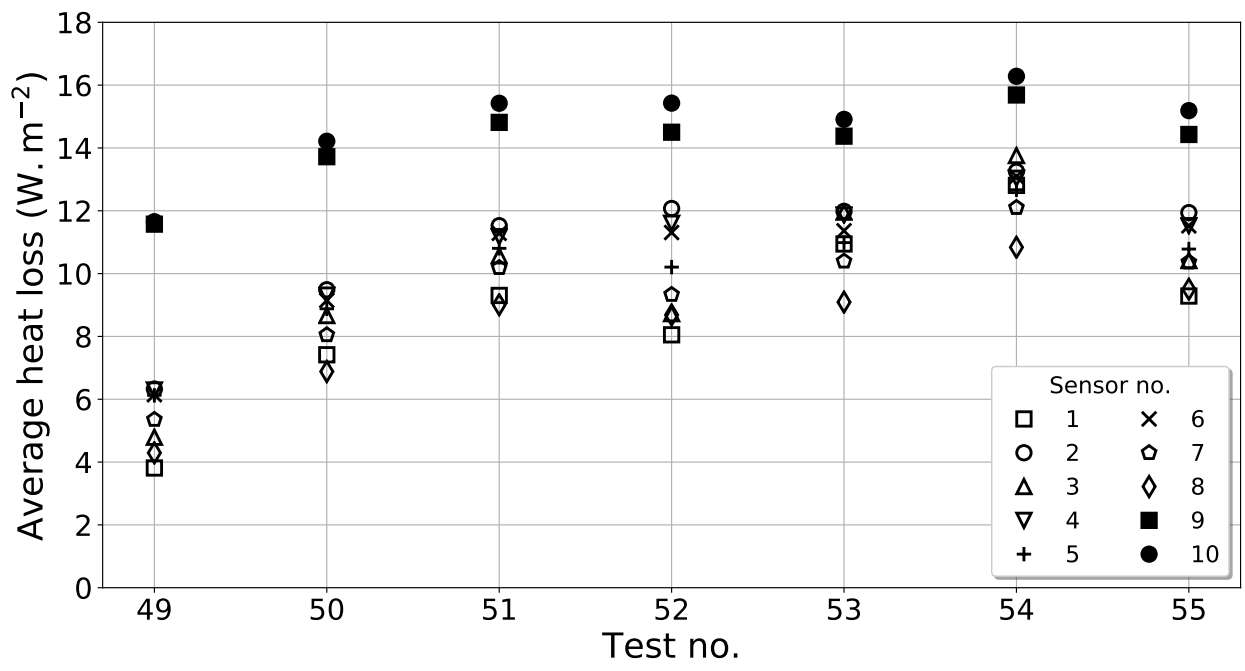

Figure 8: Average floor heat flux from the perimeter and core heat flux sensors on a daily basis for a typical week of testing (full symbols: perimeter sensors, empty symbols: core sensors) - Increased airtightness configuration

Having determined the average floor heat flux $\left(\mathrm{W} \mathrm{m}^{-2}\right)$, qfloor, avg, as determined from the ten heat flux sensors that were installed on the floor, the rate of heat loss to the ground (W) was calculated by multiplying this value with the total floor area, $A_{\text {floor }}$. This was then subtracted from the average rate of heat loss (product of the HTC and the average temperature difference during the test, $\Delta \mathrm{T}_{\mathrm{avg}}$ ) from the whole house during the test in order to determine the average power lost from those building elements that were in direct contact to the outside temperature, $\mathrm{P}_{\text {ext }}$ as described in Equation 4. Finally, the adjusted HTC, $\mathrm{H}_{\text {adj }}$, related only to losses due to the external temperature was determined by dividing $\mathrm{P}_{\text {ext }}$, by the average difference between the internal and external temperature during the test (Equation 5). 


$$
\begin{aligned}
P_{e x t} & =H \Delta T_{\text {avg }}-q_{\text {floor, avg }} A_{\text {floor }} \\
H_{\text {adj }} & =\frac{P_{\text {ext }}}{\Delta T_{\text {avg }}}
\end{aligned}
$$

\section{Results and discussion}

The analysis focused on evaluating the ability of the QUB method to provide robust results and the effect of specific weather and testing conditions. Results reported here are from these tests that successfully met the requirement of maintaining the value of the $\alpha$-parameter within the recommended limits. A detailed discussion on the influence of the $\alpha$-parameter on the HTC estimates can be found in [21].

\subsection{Results consistency}

Figure 9 represents the HTC estimates, noted $\hat{\mathrm{H}}$, and their associated uncertainties, obtained for each QUB test for both the baseline and the increased airtightness configurations. The dashed black lines represent the mean values, the dark grey and grey shaded areas correspond to deviations of $\pm 10 \%$ and $\pm 20 \%$ from the mean values. Descriptive statistics of the measurements and estimates of the population mean are reported in Table 2.

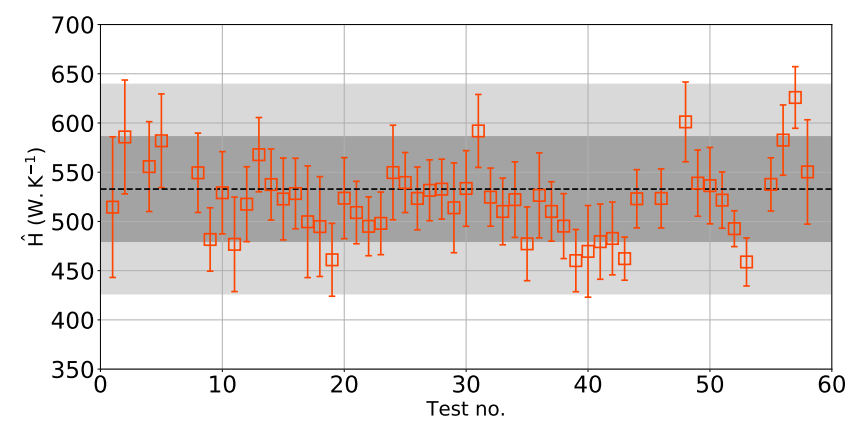

(a) Baseline

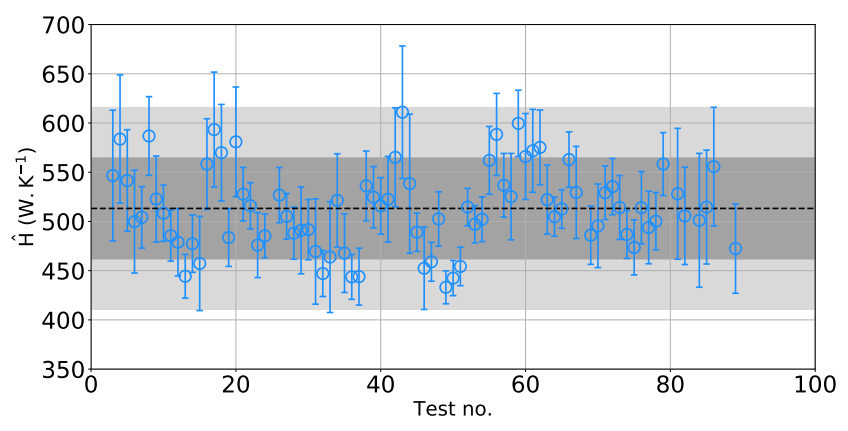

(b) Increased airtightness

Figure 9: HTC estimates for each QUB test for the baseline and increased airtightness configurations. The dashed black lines represent the mean values, the dark grey and grey shaded areas correspond to deviations of $\pm 10 \%$ and $\pm 20 \%$ from the mean values.

\begin{tabular}{cccccc}
\hline Configuration & No. of tests & \multicolumn{4}{c}{ HTC $\left(\mathrm{W} \mathrm{K}^{-1}\right)$} \\
\cline { 3 - 6 } & & mean & SD $(\mathrm{CoV})$ & SEM & $\mathrm{U}_{95}$ \\
\hline Baseline & 52 & 522.3 & $37.3(7.1 \%)$ & 5.2 & 10.5 \\
Increased airtightness & 81 & 513.2 & $41.8(8.1 \%)$ & 4.7 & 9.3 \\
\hline
\end{tabular}

Table 2: Descriptive statistics of the measurements and estimates of the population mean $(\mathrm{SD}=$ Standard Deviation, $\mathrm{CoV}=$ Coefficient of Variation, $\mathrm{SEM}=$ Standard Error of the Mean, $\mathrm{U}_{95}=$ absolute uncertainty of the mean for 95\% confidence interval) - Baseline and increased airtightness configurations

The mean relative uncertainty associated with the HTC estimate of each QUB test is $7.2 \%$ for both configurations. This is close to the values of the standard deviations (SD) of the HTC estimates (see Table 2).

The mean HTCs, and their associated $95 \%$ confidence intervals, are $522.3 \pm 10.5 \mathrm{~W} \mathrm{~K}^{-1}( \pm 2.0 \%)$ and 513.2 $\pm 9.3 \mathrm{~W} \mathrm{~K}^{-1}( \pm 1.8 \%)$ for the baseline configuration and the increased airtightness configuration, respectively.

All the HTC estimates obtained from the 133 (out of 147) QUB tests which fulfilled a value of the $\alpha$ parameter within the recommended limits lay within $\pm 20 \%$ of the mean values for both the baseline and the increased airtightness configurations. With regards to the baseline configuration, 42 results were within $\pm 10 \%$ from the mean value and further 9 results were within $\pm 15 \%$. In total $98 \%$ of the results (i.e. 51 out of 52 ) were found to be within $\pm 15 \%$ from the mean. With regards to the increased airtightness configuration, 59 results 
(i.e. $73 \%$ of all results reported) were within $\pm 10 \%$ from the mean while additional 19 results were within \pm $15 \%$; only in 3 cases (out of a total of 81 tests) results approached but not exceeded the $\pm 20 \%$ threshold. In total, $96 \%$ of the results (i.e. 78 out of 81 ) were found to be within $\pm 15 \%$ from the mean. This suggests that the QUB method had good levels of repeatability and robustness.

The distributions of the HTC estimates obtained for the baseline and the increased airtightness configurations are shown in Figure 10. The boxes represent the $25^{\text {th }}, 50^{\text {th }}$ and $75^{\text {th }}$ percentiles of the two sets of data and the whiskers extend up to 1.5 times the interquartile range outside the box boundaries. Dots that appear outside the whiskers are considered outliers. Out of a total of 133 tests for both configurations, there is one result in the baseline configuration that statistically appears to be an outlier; even in this case however, that result is still within the $20 \%$ from the mean value. In both cases, duration of the test did not cause a systematic effect on the results as the heating phase was at all times sufficiently long (i.e. longer than 5 hours of heating or 10 hours for the total test duration).

In practical terms, this means that a QUB test may be performed from late September until late March in UK for the type of building investigated in this study. This is consistent with the recommended testing period for coheating tests in UK. However, it should be noted that previous research indicates that the QUB method can be used all year long (e.g., $[16,24]$ and references therein), in particular for buildings with a low to medium thermal mass. Further evidence is needed for the type of building investigated in this study.

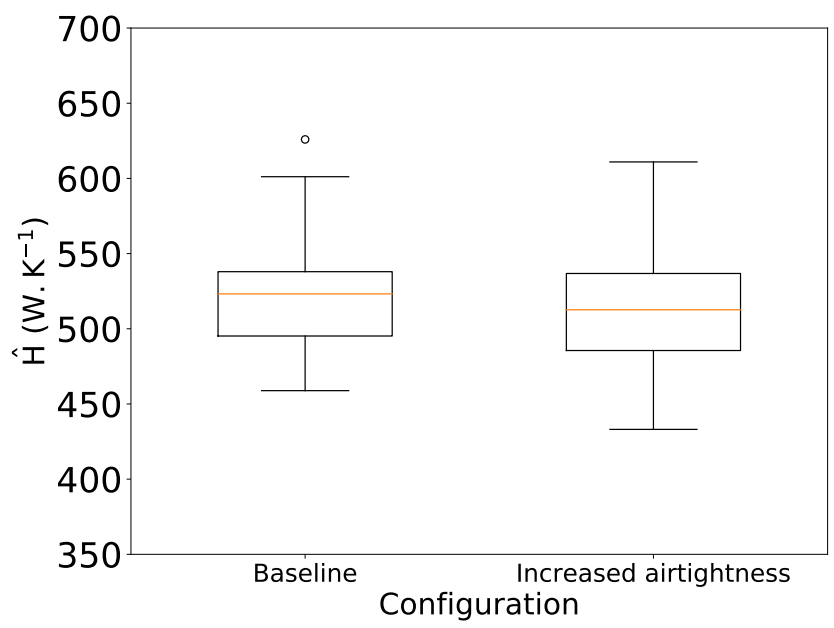

Figure 10: Box plot of the HTC estimates for the baseline and the increased airtightness configurations

\subsection{Airtightness and infiltration losses}

Reduction in the mean HTC as a result of increasing the airtightness of the building was $9.1 \pm 14.0 \mathrm{~W} \mathrm{~K}^{-1}$. The absolute uncertainty was computed from the absolute uncertainties associated with a $95 \%$ confidence interval of the mean HTC estimates. The reduction was deemed not significant since the confidence intervals overlap (see Figure 10). This was confirmed with T-tests performed on the two distributions which suggest that we cannot reject the null hypothesis of identical mean values $(\mathrm{p}$-value $=0.20)$.

It should be noted that a simplified theoretical calculation based on the Standard Assessment Procedure which takes into account the monthly wind data for the site location, the shelter factor and the building ventilation characteristics [6] showed an estimated reduction of the infiltration heat losses by $17.3 \mathrm{~W} \mathrm{~K}^{-1}$ of the increased airtightness compared to the baseline configuration. It is should be noted that the two values refer to different weather conditions (the SAP calculation is based on average regional wind data while the experimental results reflect the average on-site weather conditions of the testing period) and therefore some discrepancy was expected in any case.

\subsection{Weather conditions}

The effect of the main weather parameters was investigated in an attempt to explain part of the variance of the results and understand the performance of the method in situ. The parameters investigated were the wind conditions, external temperature and solar radiation. 


\subsubsection{Wind conditions}

Wind conditions are likely to affect the measured HTC of a building through increased infiltration losses, wind washing and thermal bypass $[7,10,28]$. Several research studies investigated the impact of wind conditions on infiltration losses during coheating tests [10,28-30]. Stamp [10] reported the findings of several field tests attempting to find a correlation between wind speed and the whole building HTC. It was found that in some cases there was no correlation and in some cases a relationship between these two variables could be established. In the work reported here, no significant effect of the wind conditions was observed and this was attributed to the low wind speeds experienced throughout the testing period and the fact that the building under investigation was sheltered from the three sides. The maximum average wind speed did not exceed $3 \mathrm{~m} \mathrm{~s}^{-1}$ during the baseline configuration testing while the $3 \mathrm{~m} \mathrm{~s}^{-1}$ threshold was only exceeded in 5 tests during the increased airtightness testing reaching a maximum just below $3.7 \mathrm{~m} \mathrm{~s}^{-1}$. Infiltration in buildings is the combined effect of stack and wind induced ventilation with the former being the dominant factor at low wind speeds. A more comprehensive discussion on the results obtained and the weak relationship between wind conditions and HTC can be found in $[21]$.

\subsubsection{Solar radiation}

In addition, solar radiation was not found to have a significant effect on the building's HTC. The effect of solar radiation on the experimental assessment of a building's HTC has been identified as major contributor to uncertainty in coheating tests though the time lag of the building's thermal response to solar gains and the increase of internal temperatures higher than the temperature setpoint of the test in buildings with large areas of south facing glazing [10]. As the QUB test takes place during the night it is apparent that solar gains do not directly affect the temperature evolution; the time lag from solar gains stored in the building fabric and readmitted later in the building however could affect a QUB measurement.

In both cases it was found that there was no correlation between the resulting HTC and the levels of solar gains at the day prior to the QUB test. This was true considering for global horizontal and vertical south irradiance for both the baseline and the increased airtightness configurations. One reason for this is that the house under investigation has very large heat losses and any contribution of solar gains might simply be very small compared to the HTC to make a difference. This can be seen in Figure 11 where the evolution of the average internal temperature in the house is shown during the preheating stage and during the test. The timers were set so that the preheating stage would finish approximately 10 minutes before the test commenced. It can be seen that the internal temperature dropped about $1.5 \mathrm{~K}$ within these 10 minutes. Therefore, it is reasonable to assume that the thermal inertia of the building did not play a significant role because the heat losses were far greater than any heat gains readmitted back to space. This becomes more prominent as the analysis of QUB considers the internal temperature slopes during the last few hours of each phase $\left(\mathrm{T}_{1}^{\prime}\right.$ and $\mathrm{T}_{2}^{\prime}$ respectively in Equation 2); any effect from solar gains stored in the building's envelope and readmitted back to space should be diminished by that time.

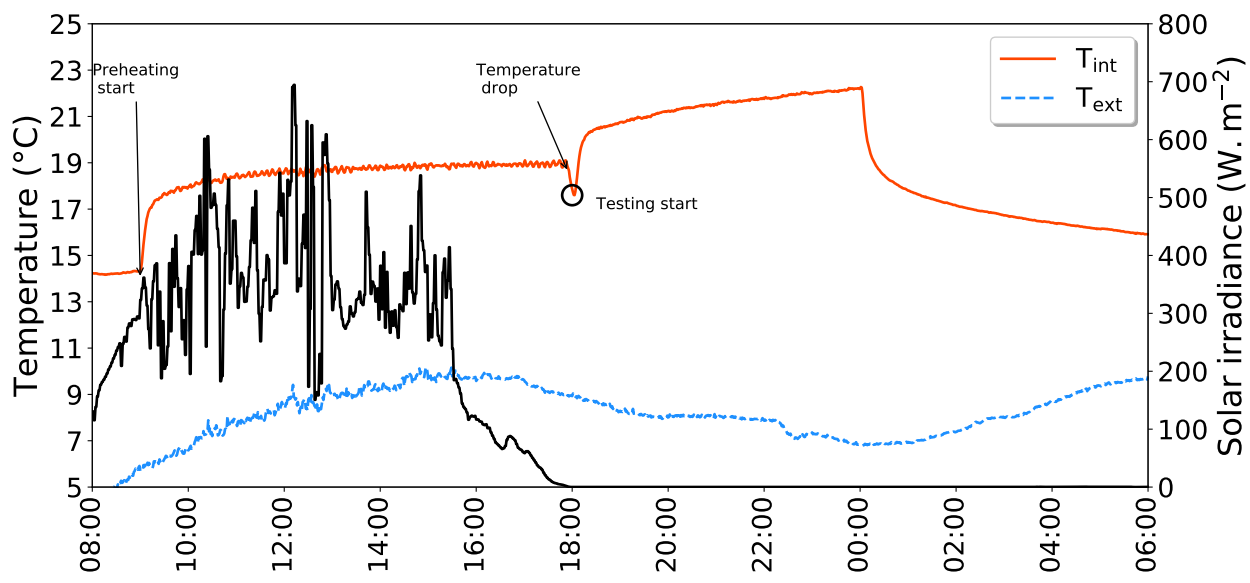

Figure 11: Internal temperature evolution prior to and during a QUB test

\subsection{Ground losses}

Another factor investigated in an attempt to increase consistency of the results was the effect of the ground floor losses on the HTC. Losses though the ground floor occur due to the ground rather than the external 
temperature; ground temperature is influenced by a large thermal mass and therefore does not follow the air temperature variation. The consequence of this is that the floor temperature is very slow to change (over weeks rather than days) and therefore floor losses are somewhat independent from the rest of the building envelope.

It should be noted that the majority of the heat flux sensors were installed in January 2017 and therefore the results reported refer to the period from January 2017 onwards, i.e. for the vast majority of the tests (58 out of 89) of the increased airtightness.

The distributions of the results in terms of the whole building HTC and the adjusted HTC for that period are presented in Figure 12. Again, boxes in the box plot graph represent the $25^{\text {th }}, 50^{\text {th }}$ and $75^{\text {th }}$ percentiles of the two sets of data and the whiskers extend up to 1.5 times the interquartile range outside the box boundaries. Descriptive statistics of the measurements and estimates of the population mean are reported in Table 2.

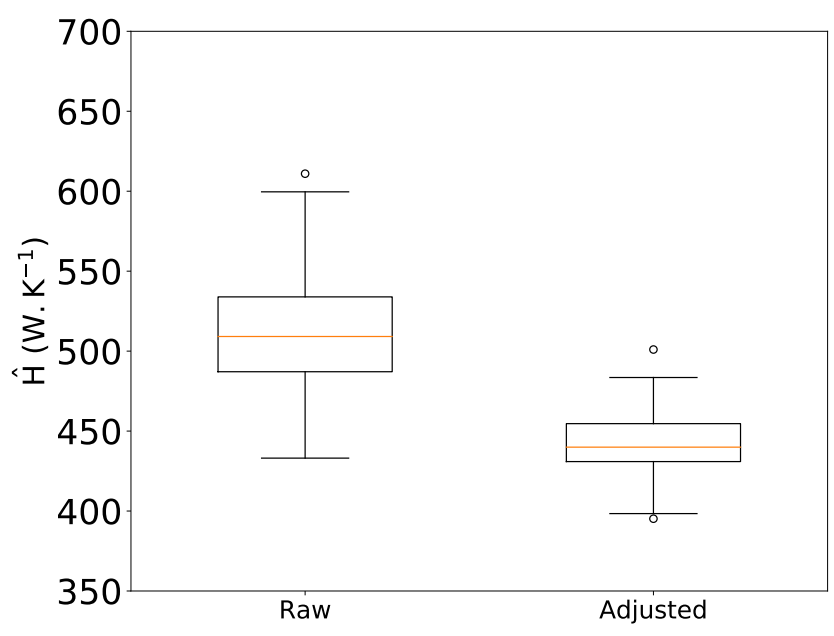

Figure 12: Box plot of the HTC and the adjusted HTC estimates for the increased airtightness configuration

\begin{tabular}{cccccc}
\hline \multirow{2}{*}{ No. of tests } & \multicolumn{4}{c}{ HTC $\left(\mathrm{W} \mathrm{K}^{-1}\right)$} \\
\cline { 3 - 6 } & & mean & SD (CoV) & SEM & $\mathrm{U}_{95}$ \\
\hline Raw & 58 & 510.6 & $41.0(8.0 \%)$ & 5.4 & 10.9 \\
Adjusted & 58 & 442.7 & $22.2(5.0 \%)$ & 2.9 & 5.9 \\
\hline
\end{tabular}

Table 3: Descriptive statistics of the measurements and estimates of the population mean $(\mathrm{SD}=$ Standard Deviation, CoV $=$ Coefficient of Variation, SEM = Standard Error of the Mean, U95 $=$ absolute uncertainty of the mean for $95 \%$ confidence interval) - Increased airtightness configuration

The mean HTCs, and their associated 95\% confidence intervals, for the period between January $17^{\text {th }}$ and March $21^{\text {st }}$ (58 tests, increased airtightness configuration) were $510.6 \pm 10.9 \mathrm{~W} \mathrm{~K}^{-1}( \pm 2.1 \%)$ and $442.7 \pm$ $5.9 \mathrm{~W} \mathrm{~K}^{-1}( \pm 1.3 \%)$ for the HTC and the adjusted HTC, respectively. The mean estimate of the ground losses, noted $\hat{\mathrm{H}}_{\mathrm{G}}$ with $\hat{\mathrm{H}}_{\mathrm{G}}=\hat{\mathrm{H}}-\hat{\mathrm{H}}_{\mathrm{adj}}$, was thus $67.9 \pm 12.4 \mathrm{~W} \mathrm{~K}^{-1}$. The absolute uncertainty was computed from the absolute uncertainties associated with a $95 \%$ confidence interval of the mean HTC estimates. The ground losses contributed to $13.3 \pm 2.4 \%$ of the whole HTC.

It can be seen that when the floor heat losses are isolated, the adjusted HTC values are less dispersed (i.e., the $\mathrm{CoV}$ is lower than for the whole house HTC values).

All adjusted HTC estimates were within $\pm 10 \%$ from the mean in all but two cases (56 out of 58 results). Two HTC estimates were deemed statistical outliers within $\pm 13 \%$ from the mean, well below the $\pm 20 \%$ threshold. This is considered an improvement compared to the results for the whole building HTC where the outlier was close to but not exceeding the $\pm 20 \%$ threshold.

This suggests that the assumption of increased heat losses occurring through the ground on tests with higher starting temperature was valid. Higher starting temperatures led to higher whole house HTC on those tests and consequently to increased variability in the results. The need to take into consideration the floor losses is therefore highlighted when evaluating the results of a QUB test (or any other whole building testing method), especially in the case of an uninsulated concrete floor.

This finding is consistent with previous studies. Everett et al. [29] isolated both floor and infiltration losses from the HTC in the 'Thermal calibration' method. Stamp [10] also discussed the uncertainty introduced to 
coheating tests from the ground floor losses. Research on the thermal performance of uninsulated concrete floors has showed the spatial variation on the heat losses closer to the perimeter (e.g., see [31-33]) while Jack [34] recommended quantifying the ground floor losses as a topic of future research to advance knowledge on the uncertainty in coheating tests.

\section{Conclusions}

The findings from the first long-term field study to evaluate the robustness of the QUB method on site conducted in a circa 1950s detached dwelling were presented in this work. The objectives of the study were to assess the repeatability of the results and reliance of the method to the prevalent test conditions. The study which was the first part of a two-year campaign conducted to investigate the applicability of QUB in the field under the UK weather conditions. The tests were conducted on a daily basis from the end of September 2016 until the end of March 2017 under two distinct airtightness configurations. Results were not affected by the prevalent weather conditions during the heating season in this particular case, suggesting that the QUB method may be applied during most of the heating season under commonly occurring weather conditions without loss in accuracy for this type of building. In total 147 tests were conducted, which represents a significant test sample in this field and as such provides confidence in the findings of the obtained results. The following conclusions were drawn from the analysis:

- The QUB method was able to provide consistent and robust estimates of the HTC with approximately $80 \%$ of the results within $\pm 10 \%$ from the mean and more than $95 \%$ of the results within $\pm 15 \%$. The requirement for $80 \%$ accuracy of a short test as reported in the Good Homes Alliance report was met in all occasions.

- The need to treat heat losses occurring through the ground when assessing the thermal performance of buildings through experimental diagnostics methods was highlighted, especially in uninsulated concrete slab floors. Isolating the ground floor heat losses from the whole building losses resulted in reduced dispersion of the adjusted HTC with a coefficient of variation of $5 \%$ and $98 \%$ of the results within $\pm 10 \%$ from the mean. Robustness of the method is therefore increased for the case examined when considering losses from building elements in direct contact to the external temperature.

The QUB method is able to estimate the HTC of a building within just one night. This is significantly less than the 2-4 week period required for a coheating test or other quasi steady-state methods suggesting that the QUB method has the potential to be used not only as a research tool but also as a diagnostics tool in industry. Furthermore, results are obtained instantly, as opposed to other methods that may require an additional period for post-processing analysis. This fits well with the timescales required by industry and building performance evaluation practitioners.

It should be noted that this study is considered the first step in validating the QUB method on site and its findings are applicable to this type of building examined. In order to generalize these findings, further research is recommended in buildings of different typologies and construction methods as well as buildings with higher levels of insulation. Additionally, it would be useful to examine a wider range of preheating regimes in order to gain a better insight on the variability caused by the test starting temperature. Finally, assessing the effect of additional weather parameters such as precipitation and the radiative losses to the sky will be useful to examine and assess their potential contribution in the observed variation in the results.

\section{Acknowledgements}

The authors gratefully acknowledge funding received from Saint-Gobain and Innovate UK under the KTP009930 project.

\section{References}

[1] DECC (2011). The Carbon Plan: Delivering our low carbon future. Department of Energy and Climate Change, London, UK.

[2] DBEIS (2016). Digest of United Kingdom Energy Statistics (DUKES) Energy: Chapter 1. Department for Business, Energy and Industrial Strategy.

[3] Cutland Consulting Limited (2012). Low and Zero Carbon Homes: Understanding the Performance Challenge. NHBC Foundation and IHS BRE Press, Watford, UK. 
[4] Zero Carbon Hub (2014). Closing the Gap Between Design and As-built Performance - Evidence Review Report. London, UK.

[5] BSI (2017). BS EN ISO 13789:2017. Thermal performance of buildings. Transmission and ventilation heat transfer coefficients. Calculation method. British Standards Institution (BSI), London, UK.

[6] DECC (2014). The Government's Standard Assessment Procedure for Energy rating of Dwellings, 2012 edition. BRE, Garston, UK.

[7] D. Johnston, D. Miles-Shenton, D. Farmer and J. Wingfield (2013). Whole House Heat Loss Test Method (Coheating). Leeds Metropolitan University, Leeds, UK.

[8] G. Bauwens and S. Roels (2014). Co-heating test: A state-of-the-art. Energy and Buildings, vol. 82, pp. 163 - 172. https://doi.org/10.1016/j.enbuild.2014.04.039

[9] J. White (2014). An investigation into the parameters that contribute to the gap between the designed and as-built thermal performance of British housing. PhD thesis, The University of Nottingham, Nottingham, UK.

[10] S. Stamp (2015). Assessing Uncertainty in co-heating tests: Calibrating a whole building steady state heat loss measurement method. $\mathrm{PhD}$ thesis, University College London, London, UK.

[11] R. Jack, D. Loveday, D. Allinson and K. Lomas (2018). First evidence for the reliability of building coheating tests. Building Research 83 Information, vol. 46 (4), pp. 383 - 401. https://doi.org/10.1080/ 09613218.2017 .1299523

[12] GHA (2011). GHA Monitoring Programme 2009-11: Technical Report, Results from Phase 1: Postconstruction testing of a sample of highly sustainable new homes. Good Homes Alliance.

[13] A. Janssens (2016). Overview of Methods to Analyse Dynamic Data. International Energy Agency, EBC Annex 58, Reliable building energy performance characterisation based on full scale dynamic measurements. KU Leuven, Leuven, Belgium.

[14] S. Rouchier, M.J. Jiménez and S. Castao (2019). Sequential Monte Carlo for on-line parameter estimation of a lumped building energy model. Energy and Buildings, vol. 187, pp 86-94. https://doi.org/10. 1016/j.enbuild.2019.01.045

[15] M. Senave, G. Reynders, P. Bacher, S. Roels, S. Verbeke and D. Saelens (2019). Towards the characterization of the heat loss coefficient via on-board monitoring: Physical interpretation of ARX model coefficients. Energy and Buildings, vol. 195, pp 180 - 194. https://doi.org/10.1016/j.enbuild.2019.05.001

[16] F. Alzetto, G. Pandraud, R. Fitton, I. Heusler and H. Sinnebichler (2018). QUB: a fast dynamic method for in-situ measurement of the whole building heat loss. Energy and Buildings, vol. 174, pp $124-133$. https://doi.org/10.1016/j.enbuild.2018.06.002

[17] C. Ghiaus and F. Alzetto (2019). Design of experiments for Quick U-building (QUB) method for building energy performance measurement. Journal of Building Performance Simulation, vol. 12 (4), pp $465-479$. https://doi.org/10.1080/19401493.2018.1561753

[18] N. Ahmad, C. Ghiaus and T. Thiery (2020). Influence of Initial and Boundary Conditions on the Accuracy of the QUB Method to Determine the Overall Heat Loss Coefficient of a Building. Energies, vol. 13 (1), 284. https://doi.org/10.3390/en13010284

[19] J. Meulemans, F. Alzetto, D. Farmer and C. Gorse (2017). QUB/e A novel transient experimental method for in situ measurements of the thermal performance of building fabrics. In: Gorse, C. and Dastbaz, M. (eds), Building Information Modelling, Building Performance, Design and Smart Construction, Springer, Cham, Switzerland. https://doi.org/10.1007/978-3-319-50346-2_9

[20] F. Alzetto, D. Farmer, R. Fitton, T. Hughes and W. Swan (2018). Comparison of whole house heat loss test methods under controlled conditions in six distinct retrofit scenarios. Energy and Buildings, vol. 168, pp 35 - 41. https://doi.org/10.1016/j.enbuild.2018.03.024

[21] V. Sougkakis, J. Meulemans, F. Alzetto, C. Wood, M. Gillott and T. Cox (2017). An assessment of the QUB method for predicting the whole building thermal performance under actual operating conditions. In: Gorse, C. (Ed.) International Sustainable Ecological Engineering Design for Society (SEEDS) Conference 2017 - Conference Proceedings, 13 - 14 September 2017, Leeds, UK. Leeds Beckett University, Leeds, UK. https://hal.archives-ouvertes.fr/hal-01589204 
[22] V. Sougkakis, J. Meulemans, C. Wood, M. Gillott and T. Cox (2018). QUB/e: Validation of a transient method for determining whole building thermal performance and building element U-values in situ under actual operating conditions. In S. Riffat, Y. Su, D. Liu, and Y. Zhang, editors, The 17th International Conference on Sustainable Energy Technologies - SET 2018, volume 3, pages 174-184, 21 - 23 August 2018, Wuhan, China. University of Nottingham, Nottingham, UK. https://nottingham-repository. worktribe.com/output/1607959

[23] J. Meulemans (2019). An assessment of the QUB/e method for fast in situ measurements of the thermal performance of building fabrics in cold climates. In: Johansson D., Bagge H., Wahlström A. (eds) Cold Climate HVAC 2018, Springer Proceedings in Energy. Springer, Cham, Switzerland. https://doi.org/ 10.1007/978-3-030-00662-4_27

[24] F. Alzetto, J. Meulemans, G. Pandraud and D. Roux (2018). A perturbation method to estimate building thermal performance. Comptes Rendus Chimie, vol. 21 (10), pp 938 - 942. https://doi.org/10.1016/j . crci.2018.09.003

[25] H.W. Coleman and G.W. Steele (2009). Experimentation, Validation, and Uncertainty Analysis for Engineers. John Wiley \& Sons, Inc., Hoboken, New Jersey.

[26] ATTMA (2016). Technical Standard L1. Measuring Air Permeability in the Envelopes of Dwelling. Air Tightness Testing \& Measurement (ATTMA), Amersham, UK.

[27] BSI (2015). BS EN ISO 9972:2015. Thermal performance of buildings. Determination of air permeability of buildings. Fan pressurization method. British Standards Institution (BSI), London, UK.

[28] M. Siddall, J. Trinick and D. Johnston (2013). Testing the real heat loss of a Passivhaus building: Can the UK's energy performance gap be bridged? In: Proceedings of the $1^{\text {th }}$ International Passivhaus Conference 2013, 19 - 20 April 2013, Congress Center Messe Frankfurt, Frankfurt, Germany, pp. 159 - 166.

[29] R. Everett, A. Horton and J. Doggart (1985). Linford Low Energy Houses. Energy Research Group, Open University, Milton Keynes, UK.

[30] D. Miles-Shenton, J. Wingfield, R. Sutton and M. Bell (2010). Temple Avenue Project Part 1: Temple Avenue field trial Evaluation of design 6 construction process and measurement of fabric performance of new build dwellings. Leeds Metropolitan University, Leeds, UK.

[31] H.A. Trethowen and A.E. Delsante (2000). A Four-Year Site Measurement of Heat Flow in Slab-on-Ground Floors with Wet Soils. BRANZ, Porirua, New Zealand.

[32] A.E. Delsante (1989). Steady-State Heat Losses from the Core and Perimeter Regions of a Slab-on-Ground Floor. Building and Environment, vol. 24 (3), pp. 253 - 257. https://doi.org/10.1016/0360-1323(89) 90039-5

[33] M.G. Davies (1993). Heat loss from a solid floor: a new formula. Building Services Engineering Research and Technology, vol. 14 (2), pp. 71 - 75. https://doi.org/10.1177/014362449301400206

[34] R. Jack (2015). Building Diagnostics: Practical Measurement of the Fabric Thermal Performance of Houses. PhD Thesis, Loughborough University, Loughborough, UK. 